\title{
Research on Product Design of Injecting Affection
}

\author{
Z. $\mathrm{Yu}$ \\ Southeast University-Monash University Joint Graduate School \\ Southeast University \\ China
}

\begin{abstract}
Injecting affection into the product design emphasizes the emotional experience and the inner emotional needs of the users'. Though the appearance design, we can highlight the product's aesthetic characteristics and interaction properties in order to bring the pleasant emotional experience for the user. This is an important factor to realize the daily life art. In this paper, emotional design is discussed from two aspects. One is the technique of expression and another is the design method. At the same time, the design method is analyzed from instinct level, behavior level, reflection level of the product emotional.
\end{abstract}

Keywords-product design; emotional design; expression; design method

\section{INTRODUCTION}

The motional factors play an important role in the success of a product design. Consumers buy products not only for the practical value, but also hope the product can bring them the joyful mood. The emotional design of the product appearance focuses on the user's emotional experience and inner emotional needs [1].Based on the integrated design for the elements, such as the morphology of product appearance, structure, color, material, texture, surface decorative pattern, the product's aesthetic characteristics and interaction properties are highlighted so that users can get emotional experience in the process of product use.

\section{TECHNIQUE OF EXPRESSION}

The emotional design of product design is one of the factors to add art to people's daily life. German Frog Design Company puts forward the design philosophy of "form follows passion", which highly praises the emotional design [2].On the premise of ensuring the product function, it brings the user a happy emotional experience with beautiful shape, colors and intelligent interaction.

To get emotional resonance, it has to stimulate the user's cerebral cortex by the product design elements, prompt the user's emotional experience by the complex perceptual activity, especially stimulate the user's memory, association and imagination by some symbolic significance in the technique of expression in the product emotional design [3].The emotional design of shape and color is mainly carried out by the visual sense while material and skin texture is mainly realized by the sense of touch.

Form. Product form is based on the sphere, cylinder, cone, cube, polyhedron bodies. The differences between size, thickness, angle, curvature, slope will also lead to the change of the psychological feelings.

Material. Due to the surface arrangement and organizational structure, the material and texture of a product have the differences between soft and hard, smooth and rough, fine and sparse and so on. The shell smooth and delicate texture of a mobile phone delicate us psychological feelings, which produces the quality of the precision instruments and self-confidence. The mesh fabric in the surface of sports shoes and sportswear used in summer gives a breathable, lightweight psychological feelings, which result in a cool, comfortable feeling experience [4].

Color. Of all the techniques of expression, the color for emotional expression is more obvious. Since the first color monitor was introduced into personal computer, the role of color in product is more and more important. The computers with colorful translucent plastic shell designed by Jonathan Ivor for Apple computer not only broke the gray monopoly on computer market, but also arouse people the desire for color[5]

\section{THE DESIGN METHOD}

The appearance's emotional design of the product is divided into 3 levels. The are the visceral level, the behavioral level and the reflective level. The visceral level pays attention to the user's experience to the appearance of the products, which is a directing feeling made by the user's vision and touch. The behavioral level focuses on the user's interaction and communication in the process of using it.It is an interactive and emotional experience. The reflective level is implicit and a higher one. It pays attention to the symbolism and cultural orientation of a product and refers to aesthetic ideal and spirit level.

\section{A. Design Method of Instinctive Level}

Emotional design in the visceral level focuses on the appearance of the product image. It acts on the user's vision directly and is the user's first impression of the product. Designers often use geometric shape and vivid bionic form. The bionic form means that the appearance of a product imitates the shapes of animal, plant and human. The lovely and interesting shapes make the users feel life and emotion. Colani, a German designer, is a typical application of bionic form. At that time, the German designers respected the rational design and functions going first. But Colani created a large number of products with the exaggerated shapes by using the principle of bionics. His rich imagination and inspiration came from the long-term observation and experience of nature. The wine bottle opener launched in Italy is designed to be a highly personalized product with colorful dress and smile. This is a typical case of bionic design of its successful application, as shown in Figure L.

Another one is the socket designed by French artist. It tries to bring enjoyment though the free shape. The socket shape by 
the arc form, combined with the special texture materials creates a personalized effect, as shown in Figure 2.

Bionic design is more and more used in various fields, from aviation to stationery products, kitchen supplies, bathroom accessories in our daily life. It has become a kind of design method widely accepted by people.

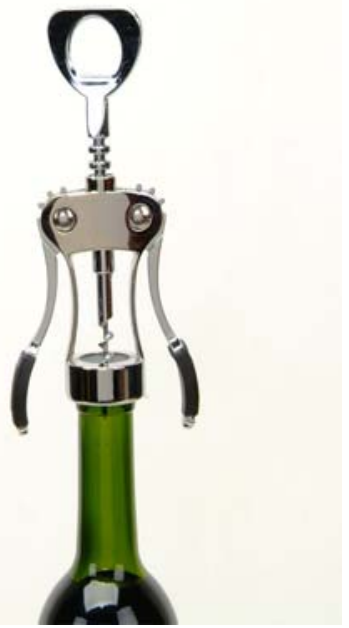

FIGURE I. BOTTLE OPENER

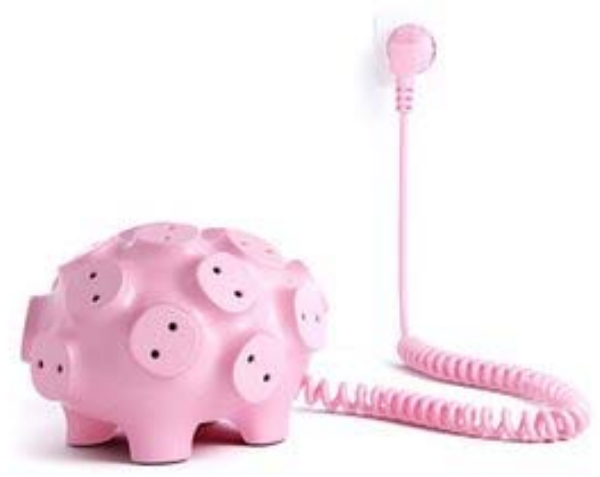

FIGURE II. SOCKET.

\section{B. Design Methods of Behavior Level}

It emphasizes the operation fun, participation, interaction in the interaction between users and products in the behavior level. Adding fun and game in the product is a common method. For example, in the design field of household appliances, colors of their shell, which is made by the temperature sensitive materials and sensor technology, can change with the change of environment temperature. That's very interesting. At the same time, it plays a role in tips. The spoon made by temperature sensing material for babies can change its color when the water's temperature is over $45{ }^{\circ} \mathrm{C}$.It is very easy to controlling the temperature of the boiling water.

Italy designers have made the summer cool pillow by using the gel material (Figure 3) and Bayesian electrical have made the super gel remote with the sense of water (Figure 4). Both of them give people a new feeling.

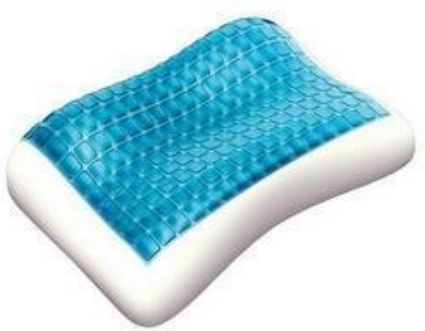

FIGURE III. SUMMER COOL GEL PILLOW

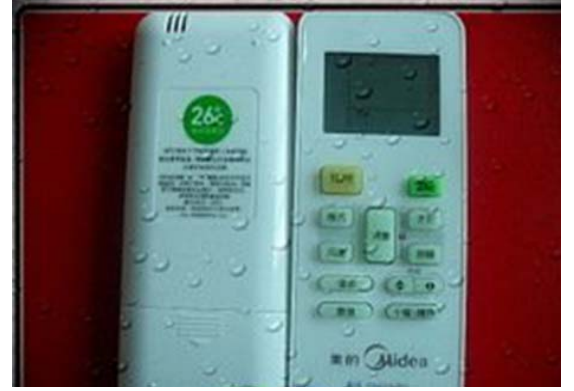

FIGURE IV. SUPER WATER SENSE GEL REMOTE

\section{Design Method of Reflection Level}

Reflection level of emotional design is the implicit and intangible level of one product, so the requirements of product design are promoted to be the culture, spiritual needs and social value level, which require the designers must have fully understanding on the symbolic meaning of a product's shape semantics and tactile semantic first, then inject the human emotion in product design. The Spanish designer Jaime Hayon has designed one kind of armchair which has a simple and sincere shape. Also its color bring person a feeling of warmth. When sitting on it, one can feel warm and comfort, just like a kids is carried in his mother's arms, as shown in figure 5.The home furnishing products made by Germany Hogri Brand Company are famous for the design of humanity humor. There always are some cute faces and vivid expression on their products. They embody the emotional design ideas. As shown in Figure 6.

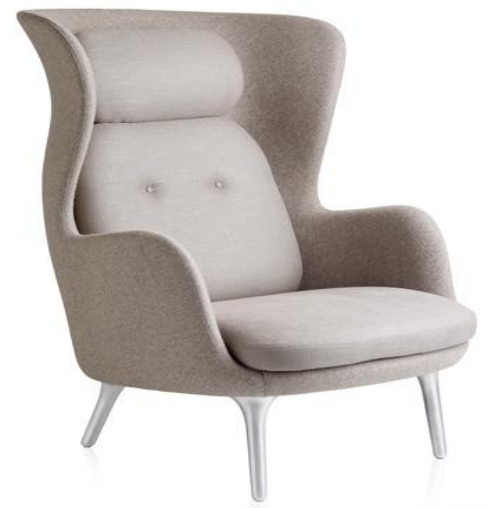

FIGURE V. MILAN 2013-RO ARMCHAIR 


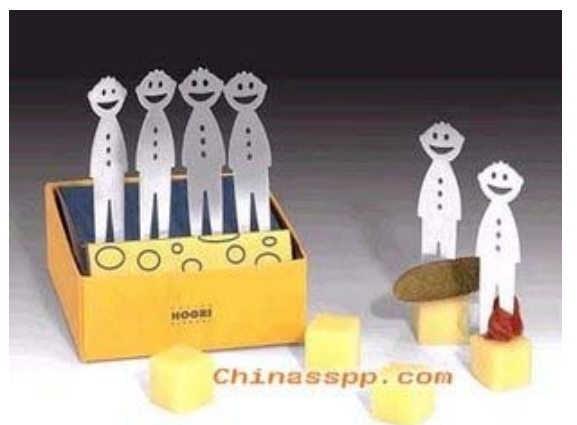

\section{FIGURE VI. GERMANY HOGRI BRAND HOME FURNISHING ACTIVITIES}

\section{CONCLUSIONS}

When the emotional factors are injected into the product design, one product has had the the effect of emotional energy, which can stimulate people's positive emotions, set up a positive attitude or evoke people's happy memories. At the same time, products endowed with life, can communicate customers more pleasantly. Emotional design has added more value for the products from the view of humanity, and becomes an important factor influencing people's life style and consumers' behavior.

\section{REFERENCES}

[1] Donald A Norman Mei Qiong [M]., design psychology, translation. Beijing: CITIC publishing house.2010.

[2] Yin Jianguo, Wu Zhijun. The approach and tendency of emotional design of [J]. Journal of Hunan University of Science and Technology: Social Science Edition,.2013 (1, 16):161 -163.

[3] Ceng Zhilin. Emotional expression analysis of [J]. packaging engineering, in the home appliance product design in 2011, 32 (20):57 60 .

[4] Kenya Hara. Design [M]. Ji Jiang Hong, translation, Guilin: Guangxi Normal University press, 2010

[5] Li Zheng. Design and emotional design [J]. the decoration, 2004 (6):15. 